\title{
Purification and characterization of bioactive secondary metabolites isolated from soil bacteria
}

\author{
Amit Pandey ${ }^{1}$, Ankita Srivastava ${ }^{2}$, Niharika Chandra ${ }^{3}$, Dheerendra Kumar ${ }^{4}$, Sunil Kumar ${ }^{5, *}$ \\ ${ }^{1,2,4}$ Research Scholar, ${ }^{3}$ Assistant Professor, ${ }^{5}$ Associate Professor, Faculty of Biotechnology, Institute of Bio-Sciences and \\ Technology, Shri Ramswaroop Memorial University, Barabanki, Uttar Pradesh, India
}

\section{*Corresponding Author:}

Email: sunil.bio@srmu.ac.in

\begin{abstract}
The search for new bioactive compounds from the natural environment has rapidly been gaining momentum with the increase in multi-drug resistant (MDR) pathogens. In the present study, the antimicrobial potential of new bacterial species has been evaluated by initial screening of fourteen soil samples. Primary and secondary screening was performed against Escherichia coli, Staphylococcus aureus and Pseudomonas aeruginosa. Four active isolates were selected for further study. Microbial strains were identified on the basis of growth conditions and other biochemical characters. One most active microbial strain was identified using 16S rRNA sequence homology and designated as Bacillus cereus (C13). Furthermore the production of secondary metabolites was done in optimized production media and the analysis involved HPLC method to identify metabolites based on retention time where 2.833 min retention time obtained using C18 column at $265 \mathrm{~nm}$ wavelength, which is similar to valinomycin antibiotic which is also secreted by Streptomyces griseus. It shows presence of bioactive secondary metabolites which is responsible for antibacterial activity of bacterial isolates.
\end{abstract}

Keywords: Antimicrobial activity, Actinomycetes, Methanolic extract, Minimum inhibitory concentration, Streptomyces.

\section{Introduction}

The production of secondary metabolites from actinobacteria has been the most economical and biotechnological source for the discovery of new antibiotics. It has already been lead to some important antimicrobial drugs like vancomycin, chloramphenicol and tetracycline. The development of new naturally occurring antimicrobial agents with novel mechanisms of action is an urgent medical need. Soil is an extensively exploited ecological niche; the inhabitants of soil produce several useful bioactive natural products, including clinically important antibiotics. However, the emergence of drug and multidrugresistant pathogens ${ }^{1}$ necessitates a continuing search for new antimicrobial compounds with potent antimicrobial activity. Searching for previously unknown microbial strains is an effective approach for obtaining new bioactive substances. Therefore, it is indeed need of the hour to search for new drugs, especially antibiotics, to control the spread of antibiotic resistant pathogens. ${ }^{2-4}$ It is well proven that microbial metabolites are rich sources for new potential therapeutic drugs. ${ }^{5,6}$ Hundreds or thousands of antibiotics have been identified from the cultures of bacteria and fungi, but only about 100 antibiotics alone have been used to treat human and animal diseases. ${ }^{7}$ The search for less toxic, more potent antibiotics from non-infective organisms, which overcome the resistance exhibited against the existing antibiotics, is most required at present. In the past, many important bioactive compounds of high commercial value have been reported to be obtained from actinomycetes. Therefore, actinomycetes are continuing to be routinely screened for new bioactive substances. As per the past reports approximately two- thirds of naturally occurring antibiotics have been isolated from actinomycetes. ${ }^{8,9} \mathrm{~A}$ wide variety of secondary metabolites can be produced from Actinomycetes, which are prolific producers of antibiotics and important suppliers to the pharmaceutical industry. ${ }^{10}$ Actinomycetes are naturally useful in the pharmaceutical industry for their apparently unrestricted capacity to produce secondary metabolites with varied chemical structures and biological activities. ${ }^{11}$ Though thousands of antibiotics have been isolated from Streptomyces, even it represents only a small fraction of the repertoire of bioactive compounds produced. ${ }^{12-14}$ Therefore, isolation of new Streptomyces from natural resources and characterization of their secondary metabolites is a valuable effort. Streptomyces species are Grampositive, aerobic microorganisms and produce about half of all known antibiotics from microorganisms. ${ }^{15}$ Streptomyces species constitutes $50 \%$ of the total population of soil actinomycetes and $75-80 \%$ of the commercially and medicinally useful antibiotics. ${ }^{16}$ The aim of the present study was to isolate antimicrobial metabolite producing bacteria from soil samples collected from different locations of Lucknow and nearby area, Uttar Pradesh, India which an ecologically reach region. This area is poorly studied and represents the diverse and largely unscreened ecosystem. The aim of the present study was to isolate antimicrobial metabolite producing bacteria from soil samples collected from different locations of Lucknow and nearby area, Uttar Pradesh, India which is an ecologically reach region. This area is poorly studied and represents the diverse and largely unscreened ecosystem. 


\section{Materials and Methods \\ Collection of Soil Samples}

In this method total 14 soil samples were collected from different places of Lucknow and its nearby area, based on its geographical location. Lucknow is situated at latitude $26055^{\prime} \mathrm{N}$ and longitude $80059^{\prime} \mathrm{E}$. There are seven blocks touching the boundary of Lucknow city. They are Malihabad, Bakshi ka Talab, Kakori, Chinhat, Sarojini nagar, Gosaiganj and Mohanlalganj. These habitats included agricultural soil, river mud, and garbage area. These habitats included the rhizosphere of plants, preserved areas and forest soils. The samples were collected to $20-40 \mathrm{~cm}$ depth after the removal of $3.0 \mathrm{~cm}$ of the upper layer of surface of soil. This region is ecological reach in diversified populations. Because of its diversified habitat chances of getting antimicrobial metabolite producing bacteria is very high. The soil samples from sterile plastic bag were sieved aseptically to remove small pieces of stone and organic matter. The sample was homogenized using sterile mortar and pestle. The samples were placed in polyethylene bags to avoid external contamination and kept in $4^{\circ} \mathrm{C}$ until pretreatment. Soil pretreatment is required for inhibiting or eliminating unwanted microorganisms.

\section{Isolation of Soil Bacteria}

In the present study one gram of dried soil was taken in $9.0 \mathrm{ml}$ of distilled water, agitated vigorously and pre-heated at $50^{\circ} \mathrm{C}$ for half an hour. Different aqueous dilution ranging from $10^{-2}$ to $10^{-5}$ of the suspension were applied onto Nutrient agar and Starch casein agar plates. Dry colonies of actinomycetes were selected and isolated. Thus isolated colonies were preserved in Glycerol based media and stored at $70^{\circ} \mathrm{C}^{13,17}$ One gram of soil was suspended in $9.0 \mathrm{~mL}$ of sterile double distilled water. The dilution was carried out up to $10^{-5}$ dilutions. Aliquots $(0.1 \mathrm{~mL})$ of $10^{-2}, 10^{-3}$, $10^{-4}$, and $10^{-5}$ were spread on the Luria agar (Himedia). To minimize the fungal growth, actidione $20 \mathrm{mg} / \mathrm{L}$, was added. The plates were incubated at $30^{\circ} \mathrm{C}$ for 24 hours. Nutrient agar medium (NA) was used as bacterial growth medium for all experiments $(3 \mathrm{~g} / \mathrm{l}$ Beef extract, $5 \mathrm{~g} / \mathrm{l} \mathrm{Peptone,} 5 \mathrm{~g} / \mathrm{l} \mathrm{NaCl}$, and $15 \mathrm{~g} / \mathrm{l} \mathrm{Agar,} \mathrm{pH}$ 6.8). Dox's agar medium was used as fungi growth medium (20 g/l Sucrose, $2.0 \mathrm{~g} / \mathrm{l} \mathrm{NaNO}_{3}, 1 \mathrm{~g} / \mathrm{l} \mathrm{Na} \mathrm{HPO}_{4}, 5 \mathrm{~g} / \mathrm{l}$ $\mathrm{MgSO}_{4}-7 \mathrm{H}_{2} \mathrm{O}, 5 \mathrm{~g} / \mathrm{l} \mathrm{KCl}$, and $15 \mathrm{~g} / \mathrm{l}$ Agar, $\mathrm{pH}$ 6.4). Based on the colony morphology, the bacterial cultures were selected and purified by secondary culture. A total of 14 bacterial species were isolated and designated as C1-14. They were used for the screening against microbial pathogens; active isolates were further characterized by the $16 \mathrm{~S}$ rRNA sequencing technique.

\section{Agar Diffusion Assay}

Antibacterial activity was determined with slight modification by using agar diffusion assay. ${ }^{18}$ Overnight broth cultures of bacteria were freshly prepared for each assay. Nutrient agar plates $(15 \mathrm{ml})$ were prepared, allowed to set and then surface dried $\left(37^{\circ} \mathrm{C}\right.$ for $\left.30 \mathrm{~min}\right)$. $500 \mu \mathrm{l}$ of bacterial culture was spread over the surface of the dried agar plates using a sterile glass spreader and allowed to absorb in the agar for $10 \mathrm{~min}$. The plates were dried, inverted, at $37^{\circ} \mathrm{C}$ for approximately $30 \mathrm{~min}$ until the bacterial overlay had dried. $10 \mu \mathrm{l}$ of the culture supernatant was pipetted onto a $6 \mathrm{~mm}$ sterile disc (Whattman filter paper), and the disc was placed onto the agar plate and incubated at $37^{\circ} \mathrm{C}$ for $24 \mathrm{~h}$. The diameters of the inhibition zone for each were recorded in $\mathrm{mm}$.

\section{Screening of Microbial Cultures}

Initially the isolated bacterial cultures were screen for their antibacterial activity by antibiotic sensitivity test method and further by 16S rRNA analysis identification and characterization was done. Identification of bacterial isolates was performed by Bergey's manual which indicates presence of Bacillus culture and 16S rRNA analysis proved that the C13 isolate was Bacillus cereus. Antibiotic sensitivity test was performed on Gram positive- Staphylococcus aureus (MTCC 2940) and Gram negativePseudomonas aeruginosa (MTCC 2453) and E. coli (MTCC739).

\section{Production and Purification of the Active metabolites}

The bacterial culture $\mathrm{C} 13$ was inoculated in production media which was prepared after optimization of bacterial culture (already published data) in the form of suitable carbon source, nitrogen source, $\mathrm{pH}$ and temperature. The production media includes glucose as carbon source, ammonium chloride as a nitrogen source, $\mathrm{pH} 7$ and temperature $37^{\circ} \mathrm{C}$. In this medium the bacterial culture was kept for 48 hours for production of metabolites. Thereafter the production media was centrifuged at $10,000 \mathrm{rpm}$ for $10 \mathrm{~min}$ to separate the biomass.

The active metabolite was recovered from the broth using two phase solvent extraction method with organic solvent. Solvents which contain the active compounds were concentrated to get "dried crude. This crude was treated with non-polar solvents like chloroform to separate the polar and non- polar components. ${ }^{19}$

\section{Extraction of Secondary Metabolites}

Secondary metabolites were extracted using solvent extraction method. Chloroform and methanol were used as solvents for the secondary metabolite extraction. The intracellular and extracellular metabolites were extracted as per standard protocol. ${ }^{20}$

Intracellular secondary metabolites extraction was carried out by dissolving pallet of bacterial broth culture into $0.5 \mathrm{ml}$ of methanol and further after mixing centrifuged at $10,000 \mathrm{rpm}$ for 10 minutes and upper layer was used for further work. 
Extracellular secondary metabolites extraction was carried out by dissolving bacterial broth culture into 0.5 $\mathrm{ml}$ chloroform and further after mixing centrifuged at $10,000 \mathrm{rpm}$ for 10 minutes and bottom layer was used for further work. The extraction of metabolites was based on the polarity of solvent. ${ }^{20}$

\section{High Performance Liquid Chromatography (HPLC)}

After the removal of cell mass, supernatant was analyzed by spectrophotometer at $265 \mathrm{~nm}$. This was carried out for HPLC analysis. $10 \mu \mathrm{l}$ of sample was injected to C18 column (250mm X 4.6mm X 5mm). The flow rate was $0.50 \mathrm{ml} / \mathrm{min}$. Sample was analyzed at $220 \mathrm{~nm}$ wavelength.

In order to purify the active fraction (methanol: chloroform 20: 80 extract); chloroform was added gradually (dropwise) until formation of the first precipitate. The precipitate was separated by centrifugation. Each fraction was tested in inhibition test. $^{21}$ Ammonium sulphate was also used for the extraction. Ammonium sulfate was grind in a glass mortar to be a fine powder that easily to dissolve. This powder was added gradually to the antagonistic solution. The solution was shacked using a vortex. The formed precipitate was separated by centrifugation. The amount of ammonium sulfate was noted for each precipitate and calculated as saturation percent. Each precipitate was dissolved in water and re-precipitated again by ammonium sulfate as a purification step. ${ }^{22}$

Each precipitate was dissolved in methanol and centrifuged to remove any residue of ammonium sulfate. This step was repeated several times until the removing all amounts of ammonium sulfate. Each precipitate was used for the inhibition test and analyzed by HPLC.

\section{Results}

Collection of soil sample: According to geographical location Lucknow is divided in 7 blocks and in this research total 14 soil samples were collected from 7 different places and out of 14 soil samples 13 bacterial isolated were found and named as C1 to C13.

Screening of the Active Strains: During the screening, thirteen bacterial cultures were isolated from seven different niches of northern India. Microbial colonies showing distinct morphological characters were selected for the primary screening. Out of 13 total bacterial isolates, four showed moderate to strong antibacterial activity against gram positive ( $S$. aureus MTCC 2940), gram negative (E. coli MTCC 739 and $P$. aeruginosa, MTCC 2453). Out of 13 active isolates, four showed strong antimicrobial activity and were selected for detailed taxonomic, physiological, and biochemical studies (Table 1).

Table 1: Activity profile zone of inhibition (zoi) of the producer strains (mm)

\begin{tabular}{|c|c|c|c|c|c|c|c|c|c|c|c|c|c|c|c|c|}
\hline \multirow{2}{*}{$\begin{array}{l}\text { MDR Test } \\
\text { strains }\end{array}$} & \multicolumn{13}{|c|}{ Soil Isolates (Bacteria) } & \multicolumn{3}{|c|}{ Known Antibiotics } \\
\hline & C1 & $\mathrm{C2}$ & $\mathrm{C3}$ & $\mathrm{C4}$ & C5 & C6 & C7 & C8 & C9 & $\mathbf{C 1 0}$ & C11 & $\mathrm{C12}$ & $\mathbf{C 1 3}$ & Amp & Tet & Ofl \\
\hline $\begin{array}{l}\text { Escherichia } \\
\text { coli } \\
\text { (MTCC739) }\end{array}$ & 16 & - & - & - & - & - & - & - & - & - & 22 & 22 & 20 & 15 & 13 & 14 \\
\hline $\begin{array}{l}\begin{array}{l}\text { Staphylococcus } \\
\text { aureus } \\
(\text { MTCC 2940) }\end{array} \\
\end{array}$ & 13 & - & - & - & - & - & - & - & - & - & 18 & 18 & 20 & 10 & 16 & 15 \\
\hline $\begin{array}{l}\text { Pseudomonas } \\
\text { aeruginosa } \\
\text { (MTCC 2453) }\end{array}$ & 16 & - & - & - & - & - & - & - & - & - & 23 & 20 & 20 & 15 & 16 & 18 \\
\hline
\end{tabular}

Note: Zone of inhibition against MDR pathogens were observed only in four bacterial cultures (C1, C11, C12 and C13).MDR: Multi drug resistant, Amp: Ampicillin, Tet: tetracycline, Ofl: Ofloxacin

Characterization of the Strains: The cultural characteristics, such as microbial growth along with its pattern and pigment formation were studied on nutrient agar medium and their results are summarized in Table 2. All the selected bacterial isolates showed moderate to heavy growth on nutrient agar medium. Different types of biochemical tests were performed for identification of bacterial isolates and the tests include: Gram's staining, Endospore staining, Catalase test, Glucose fermentation, Mannitol fermentation and MR-VP tests. $16 \mathrm{~S}$ rRNA sequence of $\mathrm{C} 13$ bacterial strain showed 99.9\% pair wise similarity with Bacillus cereus. The sequence of this strain has already been submitted in DNA Data Bank of Japan. The accession number of the sequence is LC279616 (This data has already been published). 
Table 2: Characterization of bacterial isolates having antibacterial activity against MDR pathogens

\begin{tabular}{|l|c|c|c|c|}
\hline Tests & C1 & C11 & C12 & C13 \\
\hline Grams staining & + & - & - & + \\
\hline Endospore staining & + & - & + & + \\
\hline Catalase test & + & - & + & + \\
\hline Glucose fermentation & + & - & - & + \\
\hline Mannitol fermentation & + & + & - & + \\
\hline Methyl red-Voges Proskauer test & + & - & + & + \\
\hline
\end{tabular}

+ sign indicates positive result for test and - sign indicates negative result for test.

Result of optimization of culture conditions for bacterial strains C1, C11, C12, C13: Optimization of culture condition involved best carbon source, nitrogen source, $\mathrm{pH}$ and temperature for isolates $\mathrm{C} 1, \mathrm{C} 11, \mathrm{C} 12$ and $\mathrm{C} 13$, and it was observed that glucose and ammonium chloride were found to be the best sources of carbon and nitrogen respectively. In addition to this $\mathrm{pH} 7$ and $37^{\circ} \mathrm{C}$ temperature were found to be best for optimum growth of these four bacterial cultures and salt tolerance was obtained best in $1 \%$, which is mentioned in Table 3.

Table 3: Biochemical and physiological characteristics of the producer strains

\begin{tabular}{|l|c|c|c|c|c|c|c|c|c|c|c|c|c|}
\hline Characteristics & C1 & C2 & C3 & C4 & C5 & C6 & C7 & C8 & C9 & C10 & C11 & C12 & C13 \\
\hline Assimilation & & & & & & & & & & & & & \\
\hline Glucose & +3 & -- & -- & -- & -- & -- & -- & -- & -- & -- & +3 & +3 & +3 \\
\hline Sucrose & +3 & -- & -- & -- & -- & -- & -- & -- & -- & -- & +2 & +2 & +3 \\
\hline Lactose & +2 & -- & -- & -- & -- & -- & -- & -- & -- & -- & +2 & +2 & +2 \\
\hline Mannitol & +2 & -- & -- & -- & -- & -- & -- & -- & -- & -- & +2 & +2 & +2 \\
\hline Galactose & +2 & -- & -- & -- & -- & -- & -- & -- & -- & -- & +2 & +2 & +2 \\
\hline Utilization & & & & & & & & & & & & & \\
\hline Urea & +2 & -- & -- & -- & -- & -- & -- & -- & -- & -- & +2 & +2 & +2 \\
\hline Glycine & +2 & -- & -- & -- & -- & -- & -- & -- & -- & -- & +2 & +2 & +2 \\
\hline Potassium Nitrate & +2 & -- & -- & -- & -- & -- & -- & -- & -- & -- & +2 & +2 & +2 \\
\hline Ammonium & +3 & -- & -- & -- & -- & -- & -- & -- & -- & -- & +3 & +3 & +3 \\
Chloride & & & & & & & & & & & & & \\
\hline pH tolerance & & & & & & & & & & & & & \\
\hline 5 & +2 & -- & -- & -- & -- & -- & -- & -- & -- & -- & +2 & +2 & +2 \\
\hline 7 & +3 & -- & -- & -- & -- & -- & -- & -- & -- & -- & +3 & +3 & +3 \\
\hline 9 & +2 & -- & -- & -- & -- & -- & -- & -- & -- & -- & +2 & +2 & +2 \\
\hline 11 & + & -- & -- & -- & -- & -- & -- & -- & -- & -- & + & + & + \\
\hline NaCl tolerance & & & & & & & & & & & & & \\
\hline $1 \%$ & +3 & -- & -- & -- & -- & -- & -- & -- & -- & -- & +3 & +3 & +3 \\
\hline $3 \%$ & +2 & -- & -- & -- & -- & -- & -- & -- & -- & -- & +2 & +2 & +2 \\
\hline $5 \%$ & + & -- & -- & -- & -- & -- & -- & -- & -- & -- & + & + & + \\
\hline $7 \%$ & - & -- & -- & -- & -- & -- & -- & -- & -- & -- & - & - & - \\
\hline Growth at & & & & & & & & & & & & & \\
\hline $40^{0} \mathrm{C}$ & - & -- & -- & -- & -- & -- & -- & -- & -- & -- & - & - & - \\
\hline $37^{0} \mathrm{C}$ & +3 & -- & -- & -- & -- & -- & -- & -- & -- & -- & +3 & +3 & +3 \\
\hline $55^{0} \mathrm{C}$ & - & -- & -- & -- & -- & -- & -- & -- & -- & -- & - & - & - \\
\hline
\end{tabular}

(-), No growth, (+), Poor growth, (+2), Moderate growth, (+3), Heavy growth (--), Optimization of these cultures was not done as there was no antibacterial activity as evidence by zone of inhibition in table 1 .

16S rRNA Sequencing: The 16S rRNA analysis was performed in IMTECH; Chandigarh which gives the result that $\mathrm{C} 13$ isolate was Bacillus cereus because 99 percent pairwise similarity was found (This data has already been published).

\section{HPLC Analysis}

HPLC is being routinely used for the analytical estimation of various antibiotics. In the present investigation, HPLC profile of the antimicrobial compounds of Bacillus cereus was performed by Rheodysne Column (C-18) up to $10 \mathrm{~min}$ at $265 \mathrm{~nm}$. The antimicrobial compounds of Bacillus cereus showed 
absorption peak at retention time (min) 2.833 which is similar to valinomycin antibiotic which is also secreted by Streptomyces griseus. This shows presence of bioactive secondary metabolites which is responsible for antibacterial activity of bacterial isolates (Fig. 1).



Fig. 1: HPLC analysis of secondary metabolites

\section{Discussion}

For the treatment of infectious diseases antibiotics are major compound but present time because of multidrug resistant pathogens challenges are there for treatment of diseases, so due to burden of high frequency of abnormal diseases with MDR activity it is major work to search effective antibiotics from soil bacteria like Actinomycetes or Actinobacteria.6,21,23 According to results obtained, total 14 soil samples were collected from seven different places of Lucknow, out of which total 13 bacterial cultures were obtained. Isolation of bacterial cultures was done using serial dilution method. The antibiotic sensitivity test was performed through disc diffusion method against bacterial pathogens like E. coli, S. aureus and $P$. aeruginosa which also showed MDR activity which refers that these type of culture can survive in the presence of existing antibiotics. ${ }^{21}$

During the screening of bacterial isolates, the culturing was performed in nutrient agar medium, so that the only selected bacterial community should grow and other should be inhibited. Pre-treatment of the soil samples reduced the growth of ubiquitous microbial species thereby facilitated the recovery of less-abundant microorganisms. ${ }^{24} \mathrm{~A}$ total of 13 isolated strains were subjected to antibacterial screening and it was found that four of the isolates were active against gram positive bacteria as well as gram negative bacteria. Out of 13 strains, four showed strong antibacterial activity and were selected for detailed microbial characterization studies. Further, only one strain (C13) was characterized by using $16 \mathrm{~S}$ rRNA sequencing and designated. Rest three samples were not subjected to $16 \mathrm{~S}$ rRNA sequencing as we do not have sequencing facility in our institute and it is a costly affair. Based upon the diversity achieved by the morphological and biochemical characteristics in the selected strain, we can speculate the possibility of involvement/role of diverse bioactive compounds from this strain, responsible for its broad-spectrum antimicrobial properties. The production of bioactive secondary metabolites was done in optimized production media and further these metabolites were isolated by solvent extraction method .For intracellular metabolites methanol and for extracellular metabolites chloroform was used. Further the analysis involved HPLC method to identify metabolites based on retention time where 2.833 min retention time obtained using C18 column at $265 \mathrm{~nm}$ wavelength, which is similar to valinomycin antibiotic which is also secreted by Streptomyces griseus. It shows presence of bioactive secondary metabolites which is responsible for antibacterial activity of bacterial isolates. ${ }^{21}$

\section{Conclusion}

In conclusion, the antibacterial activities achieved in this study indicate that the isolated strains have potential to produce diverse array of antibacterial compounds that can be useful for many great applications and must be explored extensively. 


\section{Acknowledgement}

Authors thank Shri Ramswaroop Memorial University, Barabanki, Uttar Pradesh, India for continuous support and assistance during the course of research work and scientific writing.

\section{Conflict of interest: None.}

\section{References}

1. Talbot GH, Bradley J, Edwards JE, Jr., Gilbert D, Scheld M, Bartlett JG. Bad bugs need drugs: an update on the development pipeline from the Antimicrobial Availability Task Force of the Infectious Diseases Society of America. Clinical infectious diseases: an official publication of the Infectious Diseases Society of America 2006 Mar 1;42(5):657-68.

2. Fischbach MA, Walsh CT. Antibiotics for emerging pathogens. Science 2009 Aug 28; 325(5944):1089-93.

3. Payne DJ, Gwynn MN, Holmes DJ, Pompliano DL. Drugs for bad bugs: confronting the challenges of antibacterial discovery. Nature reviews Drug discovery 2007 Jan;6(1):29-40.

4. Spellberg B, Guidos R, Gilbert D, Bradley J, Boucher HW, Scheld WM, Bartlett JG, Edwards J, Jr. The epidemic of antibiotic-resistant infections: a call to action for the medical community from the Infectious Diseases Society of America. Clinical infectious diseases: an official publication of the Infectious Diseases Society of America 2008 Jan 15;46(2):155-64.

5. Cragg GM, Newman DJ. Natural products: a continuing source of novel drug leads. Biochimica et biophysica acta 2013 Jun;1830(6):3670-95.

6. Jose PA, Jha B. New Dimensions of Research on Actinomycetes: Quest for Next Generation Antibiotics. Frontiers in microbiology 2016;7:1295.

7. Srividya AR, Saritha GS, Suresh B. Study of the soil isolates for antimicrobial activity. Indian journal of pharmaceutical sciences 2008 Nov;70(6):812-5.

8. Lyu A, Liu H, Che H, Yang L, Zhang J, Wu M, Chen W, Li G. Reveromycins A and B from Streptomyces sp. 3 10: Antifungal Activity against Plant Pathogenic Fungi In vitro and in a Strawberry Food Model System. Frontiers in microbiology 2017;8:550.

9. Van Minh N, Woo EE, Kim JY, Kim DW, Hwang BS, Lee YJ, Lee IK, Yun BS. Antifungal Substances from Streptomyces sp. A3265 Antagonistic to Plant Pathogenic Fungi. Mycobiology 2015 Sep;43(3):333-8.

10. Wohlleben W, Mast Y, Stegmann E, Ziemert N. Antibiotic drug discovery. Microbial biotechnology 2016 Sep;9(5):541-8.

11. Sengupta S, Pramanik A, Ghosh A, Bhattacharyya M. Antimicrobial activities of actinomycetes isolated from unexplored regions of Sundarbans mangrove ecosystem. BMC microbiology 2015 Aug 21;15:170.

12. Watve MG, Tickoo R, Jog MM, Bhole BD. How many antibiotics are produced by the genus Streptomyces? Archives of microbiology 2001 Nov;176(5):386-90.

13. Chaudhary HS, Yadav J, Shrivastava AR, Singh S, Singh AK, Gopalan N. Antibacterial activity of actinomycetes isolated from different soil samples of Sheopur (A city of central India). Journal of advanced pharmaceutical technology \& research 2013 Apr;4(2):118-23.

14. Thompson CJ, Fink D, Nguyen LD. Principles of microbial alchemy: insights from the Streptomyces coelicolor genome sequence. Genome biology 2002 Jun 26;3(7):REVIEWS1020.

15. Rahman MA, Islam MZ, Islam MA. Antibacterial activities of actinomycete isolates collected from soils of rajshahi, bangladesh. Biotechnology research international 2011;2011:857-925.

16. Mellouli L, Ben Ameur-Mehdi R, Sioud S, Salem M, Bejar S. Isolation, purification and partial characterization of antibacterial activities produced by a newly isolated Streptomyces sp. US24 strain. Research in microbiology 2003 Jun;154(5):345-52.

17. Demain AL. Microbial secondary metabolism: a new theoretical frontier for academia, a new opportunity for industry. Ciba Foundation symposium 1992;171:3-16; discussion 16-23.

18. Teh CH, Nazni WA, Nurulhusna AH, Norazah A, Lee HL. Determination of antibacterial activity and minimum inhibitory concentration of larval extract of fly via resazurin-based turbidometric assay. BMC microbiology 2017 Feb 16;17(1):36.

19. Demain AL, Adrio JL. Strain improvement for production of pharmaceuticals and other microbial metabolites by fermentation. Progress in drug research Fortschritte der Arzneimittelforschung Progres des recherches pharmaceutiques 2008;65:251,253-89.

20. Demain AL, Fang A. The natural functions of secondary metabolites. Advances in biochemical engineering/biotechnology 2000;69:1-39.

21. Singh V, Haque S, Singh H, Verma J, Vibha K, Singh R, Jawed A, Tripathi CK. Isolation, Screening, and Identification of Novel Isolates of Actinomycetes from India for Antimicrobial Applications. Frontiers in microbiology 2016;7:1921.

22. Berdy J. Bioactive microbial metabolites. The Journal of antibiotics 2005 Jan;58(1):1-26.

23. Hood JD, Box SJ, Verrall MS. Olivanic acids, a family of beta-lactam antibiotics with beta-lactamase inhibitory properties produced by Streptomyces species. II. Isolation and characterisation of the olivanic acids MM 4550, MM 13902 and MM 17880 from Streptomyces olivaceus. The Journal of antibiotics 1979 Apr;32(4):295-304.

24. Hayakawa M, Yoshida Y, limura Y. Selective isolation of bioactive soil actinomycetes belonging to the Streptomyces violaceusniger phenotypic cluster. Journal of applied microbiology 2004;96(5):973-81. 